\title{
Permissive effect of GSK3 $\beta$ on profibrogenic plasticity of renal tubular cells in progressive chronic kidney disease
}

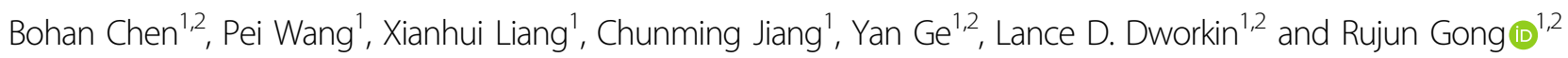

\begin{abstract}
Renal tubular epithelial cells (TECs) play a key role in renal fibrogenesis. After persistent injuries that are beyond selfhealing capacity, TECS will dedifferentiate, undergo growth arrest, convert to profibrogenic phenotypes, and resort to maladaptive plasticity that ultimately results in renal fibrosis. Evidence suggests that glycogen synthase kinase (GSK) $3 \beta$ is centrally implicated in kidney injury. However, its role in renal fibrogenesis is obscure. Analysis of publicly available kidney transcriptome database demonstrated that patients with progressive chronic kidney disease (CKD) exhibited GSK3 $\beta$ overexpression in renal tubulointerstitium, in which the predefined hallmark gene sets implicated in fibrogenesis were remarkably enriched. In vitro, TGF- $\beta 1$ treatment augmented GSK3 $\beta$ expression in TECs, concomitant with dedifferentiation, cell cycle arrest at G2/M phase, excessive accumulation of extracellular matrix, and overproduction of profibrotic cytokines like PAI-1 and CTGF. All these profibrogenic phenotypes were largely abrogated by GSK3 $\beta$ inhibitors or by ectopic expression of a dominant-negative mutant of GSK3 $\beta$ but reinforced in cells expressing the constitutively active mutant of GSK3 $\beta$. Mechanistically, GSK3 $\beta$ suppressed, whereas inhibiting GSK3 $\beta$ facilitated, the activity of CAMP response element-binding protein (CREB), which competes for CREB-binding protein, a transcriptional coactivator essential for TGF- $\beta 1 /$ Smad signaling pathway to drive TECs profibrogenic plasticity. In vivo, in mice with folic acid-induced progressive CKD, targeting of GSK3 $\beta$ in renal tubules via genetic ablation or by microdose lithium mitigated the profibrogenic plasticity of TEC, concomitant with attenuated interstitial fibrosis and tubular atrophy. Collectively, GSK3 $\beta$ is likely a pragmatic therapeutic target for averting profibrogenic plasticity of TECs and improving renal fibrosis.
\end{abstract}

\section{Introduction}

Regardless of the original etiology, kidney fibrosis, characterized by renal tubular atrophy and excessive accumulation of extracellular matrix (ECM) in tubulointerstitium, is the hallmark of progressive chronic kidney disease (CKD), the final common pathway to endstage renal failure, and the best predictor of renal survival $^{1}$. Recently, a plethora of evidence indicates that

\footnotetext{
Correspondence: Rujun Gong (Rujun.Gong@UToledo.edu)

${ }^{1}$ Division of Kidney Disease and Hypertension, Department of Medicine, Rhode Island Hospital, Brown University School of Medicine, Providence, RI 02903, USA

${ }^{2}$ Division of Nephrology, Department of Medicine, University of Toledo College of Medicine, Toledo, $\mathrm{OH} 43614$, USA
}

Edited by A. Finazzi-Agrò renal tubular epithelial cells (TECs) are centrally implicated in the development and progression of renal fibrosis $^{2,3}$. In response to various types of injuries, TECs undergo self-repair and adaptation to attain a new homeostatic equilibrium that would be compatible with their viability in the new environment. However, if the severity, frequency, or duration of the injury is beyond the repair capacity of TECs, TEC profibrogenic plasticity may arise, marked by cell dedifferentiation with distinctive features of loss of epithelial phenotypes and acquisition of mesenchymal characteristics. In addition, dedifferentiated TECs will release excess amounts of profibrotic cytokines such as connective tissue growth factor (CTGF) and plasminogen activator inhibitor-1

\section{(c) The Author(s) 2021}

(c) (i) Open Access This article is licensed under a Creative Commons Attribution 4.0 International License, which permits use, sharing, adaptation, distribution and reproduction cc) in any medium or format, as long as you give appropriate credit to the original author(s) and the source, provide a link to the Creative Commons license, and indicate if changes were made. The images or other third party material in this article are included in the article's Creative Commons license, unless indicated otherwise in a credit line to the material. If material is not included in the article's Creative Commons license and your intended use is not permitted by statutory regulation or exceeds the permitted use, you will need to obtain permission directly from the copyright holder. To view a copy of this license, visit http://creativecommons.org/licenses/by/4.0/. 
(PAI-1), which in turn act on neighboring TECs or myofibroblasts in a paracrine mode, eventually leading to ECM overproduction and kidney scarring ${ }^{4,5}$. Moreover, severely or chronically injured TECs may undergo cell cycle arrest at the G2/M phase and hence lose the ability to proliferate and repopulate the damaged tubules. Collectively, all these maladaptive plastic changes of TECs will act synthetically to cause kidney fibrosis but hinder the recovery of kidney function.

Glycogen synthase kinase (GSK) $3 \beta$ is a ubiquitously expressed serine/threonine-protein kinase that acts as an integration point for multiple cellular pathways involved in glycogen biosynthesis, inflammation, mitochondrial dysfunction, and apoptosis ${ }^{6}$. Emerging data suggest that GSK3 $\beta$ plays an instrumental role in kidney injury. In experimental glomerular diseases, podocyte-specific knockout of GSK3 $\beta$ conferred a beneficial effect on podocyte injury and glomerular damage ${ }^{7,8}$. In murine models of acute tubular injury caused by a variety of nephrotoxic insults like acute renal ischemia-reperfusion, diclofenac, or paraquat, the renal tubular activity of GSK3 $\beta$ was evidently increased, and inhibition of GSK3 $\beta$ improved renal injury by ameliorating tubular cell apoptosis and damage ${ }^{9-11}$. However, it remains obscure whether GSK3 $\beta$ is involved in renal fibrogenesis in progressive CKD. Given the primacy of TEC maladaptive plasticity in the development and progression of kidney fibrosis, this study explored the role of GSK3 $\beta$ in TEC profibrogenic plasticity and kidney fibrosis in vitro in cultured TECs treated by transforming growth factor (TGF)- $\beta 1$, and in vivo in the murine model of folic acid (FA) nephropathy.

\section{Materials and methods}

\section{Cell culture and transient transfection}

Conditionally immortalized murine proximal tubular epithelial cells (TKPT) were used as previously described ${ }^{9}$ and cultured at $37^{\circ} \mathrm{C}$ in DMEM/F12 supplemented with $5 \%$ Fetal Bovine Serum (FBS) in a humidified incubator with $5 \% \mathrm{CO}_{2}$. TKPT have been authenticated and tested for mycoplasma contamination. Cells were seeded onto $60 \mathrm{~mm}$ Petri dishes. When reaching 50\% confluency, cells were changed to serum-free DMEM/F12 for $12 \mathrm{~h}$. Thereafter, cells were stimulated with different doses of TGF- $\beta 1(0.5,1,2$, or $4 \mathrm{ng} / \mathrm{ml}$; R\&D, Minneapolis, MN, USA) for $12 \mathrm{~h}, 24 \mathrm{~h}$, or $48 \mathrm{~h}$. Alternatively, cells were pretreated with different doses of TDZD-8 $(2,5,10 \mu \mathrm{mol} /$ L; Sigma-Aldrich, St. Loius, MO, USA), lithium chloride (LiCl, 2, 5, $10 \mathrm{mmol} / \mathrm{L}$; Sigma-Aldrich) or forskolin (20 $\mu \mathrm{mol} / \mathrm{L}$, Cayman, Ann Arbor, MI, USA) for $30 \mathrm{~min}$, and thereafter treated with TGF- $\beta 1(2 \mathrm{ng} / \mathrm{ml})$ for the indicated time. The eukaryotic expression vectors encoding the haemagglutinin (HA)-conjugated dominantnegative kinase-dead (KD), or constitutively active (S9A) mutant of GSK3 $\beta$ were transfected to TKPT as previously described $^{9}$ by using Lipofectamine 2000 according to the manufacturer's instructions (Invitrogen, Carlsbad, CA, USA). After transfection, cells were subsequently subjected to the indicated treatment.

\section{Animal study \\ Murine model of FA-induced CKD}

Renal tubule-specific GSK3 $\beta$ knockout (KO) mice (C57BL/6 strain) and control littermates were generated by mating mice carrying the floxed GSK3 $\beta$ transgene with $\gamma$-glutamyltranspeptidase $(\gamma \mathrm{GT})$. Cre transgenic mice as previously elaborated ${ }^{12}$. Male $\mathrm{KO}$ or control mice aged 10 weeks were randomized (not blinded) to the following four treatment groups of six animals per group: (1) vehicle group: control mice only received vehicle treatment $(0.3 \mathrm{M}$ sodium bicarbonate) as a single intraperitoneal (ip.) injection. (2) control + FA group: control mice received a single dose of FA (ip., $250 \mathrm{mg} / \mathrm{kg}$, SigmaAldrich) dissolved in $0.3 \mathrm{M}$ sodium bicarbonate and sodium chloride (subcutaneous injection, $s c ., 1 \mathrm{mEq} / \mathrm{kg}$ ) on day 7 after FA injury. (3) $\mathrm{KO}+\mathrm{FA}$ group: $\mathrm{KO}$ mice received a single dose of FA (ip., $250 \mathrm{mg} / \mathrm{kg}$ ). (4) control $+\mathrm{FA}+\mathrm{LiCl}$ group: control mice received a single dose of FA (ip., $250 \mathrm{mg} / \mathrm{kg}$ ) and then were treated with $\mathrm{LiCl}(s c$., $40 \mathrm{mg} / \mathrm{kg}$ ) on day 7 . All mice were euthanized on day 14 after FA injection, followed by the collection of organs and serum for further investigation.

\section{PCR genotyping for transgenic mice}

A routine PCR protocol was used for genotyping tail DNA samples with the following primer pairs: for $\gamma \mathrm{GT}$. Cre genotyping, forward: 5'-AGGTGTAGAGAAGGCAC TTAGC-3' and reverse: 5'-CTAATCGCCATCTTCCAG CAGG-3', which generated a 411-bp fragment; and for GSK3 $\beta$ genotyping, forward: 5'-GGGGCAACCTTAAT TTCATT-3' and reverse: 5'-GTGTCTGTATAACTGAC TTCCTGTGGC-3', which yielded 685-bp and 585-bp bands, respectively, for the floxed and wild-type alleles.

\section{Serum blood urea nitrogen (BUN) measurements}

Serum BUN levels were measured using a commercial assay kit (BioAssay Systems, Hayward, CA, USA) according to the manufacturer's instruction.

\section{Immunohistochemistry staining}

Formalin-fixed mouse kidneys were embedded in paraffin and 3- $\mu$ m-thick sections were prepared. Sections were processed for immunohistochemistry staining. Immunoperoxidase staining was performed with a Vectastain ABC kit (Vector Laboratories, Burlingame, CA, USA) by using primary antibodies against GSK3 $\beta$ (12456, Cell Signaling Technology, MA, USA), Collagen I (sc-293182, Santa Cruz Biotechnology, CA, USA), PAI- 
1 (sc-8979, Santa Cruz Biotechnology), phosphorylated Histone H3 at serine 10 (pH3, 9701, Cell Signaling Technology) and phosphorylated cAMP response element-binding protein (CREB) at serine 133 (p-CREB, sc-81486, Santa Cruz Biotechnology). The immunoreactivity was assessed in a blind manner. The sections were visualized by using EVOS XL Core Imaging System (Thermo Fisher Scientific, Waltham, MA, USA).

\section{Immunofluorescence staining}

Cultured cells or cryosections of kidney samples were fixed with $4 \%$ paraformaldehyde (Sigma-Aldrich), permeabilized, and stained with primary antibodies against zonula occludens (ZO)-1 (617300, Invitrogen, MD, USA), E-Cadherin (3195, Cell Signaling Technology), vimentin (sc-6260, Santa Cruz Biotechnology), fibronectin (ab2413, Abcam, San Francisco, CA, USA), pH3, and CTGF (sc-14939, Santa Cruz Biotechnology), followed by Alexa Fluor-conjugated secondary antibody staining (Life Technologies, Carlsbad, CA, USA). Finally, cells or cryosections were mounted with mounting media containing propidium iodide or 4,6-diamidino-2phenylindole (DAPI, Abcam), and visualized using the EVOS FL microscope (Thermo Fisher Scientific) or the Cytation 5 cell imaging system (BioTek Instruments, Winooski, VT, USA).

\section{Western immunoblot analysis}

Cells were lysed and mouse kidneys were homogenized in radioimmunoprecipitation assay buffer supplemented with the protease inhibitor cocktail (Thermo Fisher Scientific). Samples were subjected to Western immunoblot analysis as described before ${ }^{8}$. The blots were incubated with GSK3 $\beta$, E-cadherin, vimentin, fibronectin (ab2413, Abcam; sc-9068, Santa Cruz Biotechnology), CTGF, PAI1, pH3, HA (sc-7392, Santa Cruz Biotechnology), GAPDH (sc-32233, Santa Cruz Biotechnology), and $\beta$-actin (sc81178, Santa Cruz Biotechnology). For immunoblot analysis, bands were scanned and the integrated pixel density was determined using the ImageJ analysis program, version 1.52a (National Institutes of Health, Bethesda, MD, USA).

\section{Immunoprecipitation}

Immunoprecipitation was carried out using an established method as described previously ${ }^{13}$. Briefly, nuclear fractions of cells or kidneys were prepared with the NEPER kit (Thermo Fisher Scientific) according to the manufacturer's instruction. Samples were incubated with anti-CREB-binding protein (CBP) antibody (sc-7300, Santa Cruz Biotechnology) and then precipitated by incubating with protein A/G-agarose overnight. The precipitated complexes were collected, washed, separated on SDS-polyacrylamide gels, and subjected to immunoblot analysis with anti-p-Smad2 (3108, Cell Signaling Technology), p-CREB (9198, Cell Signaling Technology), and CBP antibodies as indicated above.

\section{Morphologic analysis of human kidney tissues}

Human research participants were not specifically recruited for this study. Histology of the human kidney sections stained for GSK3 $\beta$ by peroxidase immunohistochemistry was obtained from previously published work $^{14,15}$. The kidney tissues had been originally derived from archived excessive kidney biopsy tissues from patients with focal segmental glomerulosclerosis (FSGS) or pre-implant kidney biopsy specimens. The use of unidentified human biopsy specimens had conformed to the ethical guidelines of the 1975 Declaration of Helsinki.

\section{Bioinformatics analysis}

Renal tubulointerstitial transcriptome data of 9 normal kidney tissues from healthy living donors and 18 renal biopsy tissues from patients with FSGS were derived from European Renal cDNA Bank (ERCB) nephrotic syndrome study and collected in the Nephroseq database (www. nephroseq.org). Gene set enrichment analysis (GSEA) was performed based on GSE104954 to identify biological pathways that were associated with tubulointerstitial GSK3 $\beta$ and involved in CKD pathogenesis as previously described $^{16}$. GSEA software was acquired from the Broad Institute (http://www.broad.mit.edu/gsea).

\section{Statistical analysis}

All data are expressed as mean \pm SD. All in vitro studies were repeated at least three times. Power analysis was performed to determine the adequate sample size of animal groups to measure changes in kidney function and renal injuries in a statistically significant manner. Software G*Power for sample size calculation was used as described before $^{17}$. Statistical analysis of the data from multiple groups was performed by one-way ANOVA tests followed by Tukey's tests. Data from two groups were compared by a two-sided Student's $t$-test. Statistical analyses were performed using GraphPad Prism 7.0 software (GraphPad Software, San Diego, CA, USA) or SPSS 22 (IBM Corporation, Armonk, New York, USA). $P<0.05$ was considered statistically significant.

\section{Results}

GSK3 $\beta$ is upregulated in renal tubules in progressive CKD and involved in renal fibrogenesis

Recent studies have implicated GSK3 $\beta$ in diverse kidney diseases, including glomerular diseases ${ }^{8}$, diabetic nephropathy ${ }^{18}$, and acute kidney injury (AKI) ${ }^{9}$. However, its role in progressive CKD and renal fibrosis is unclear. To address this issue, renal tubulointerstitial expression 


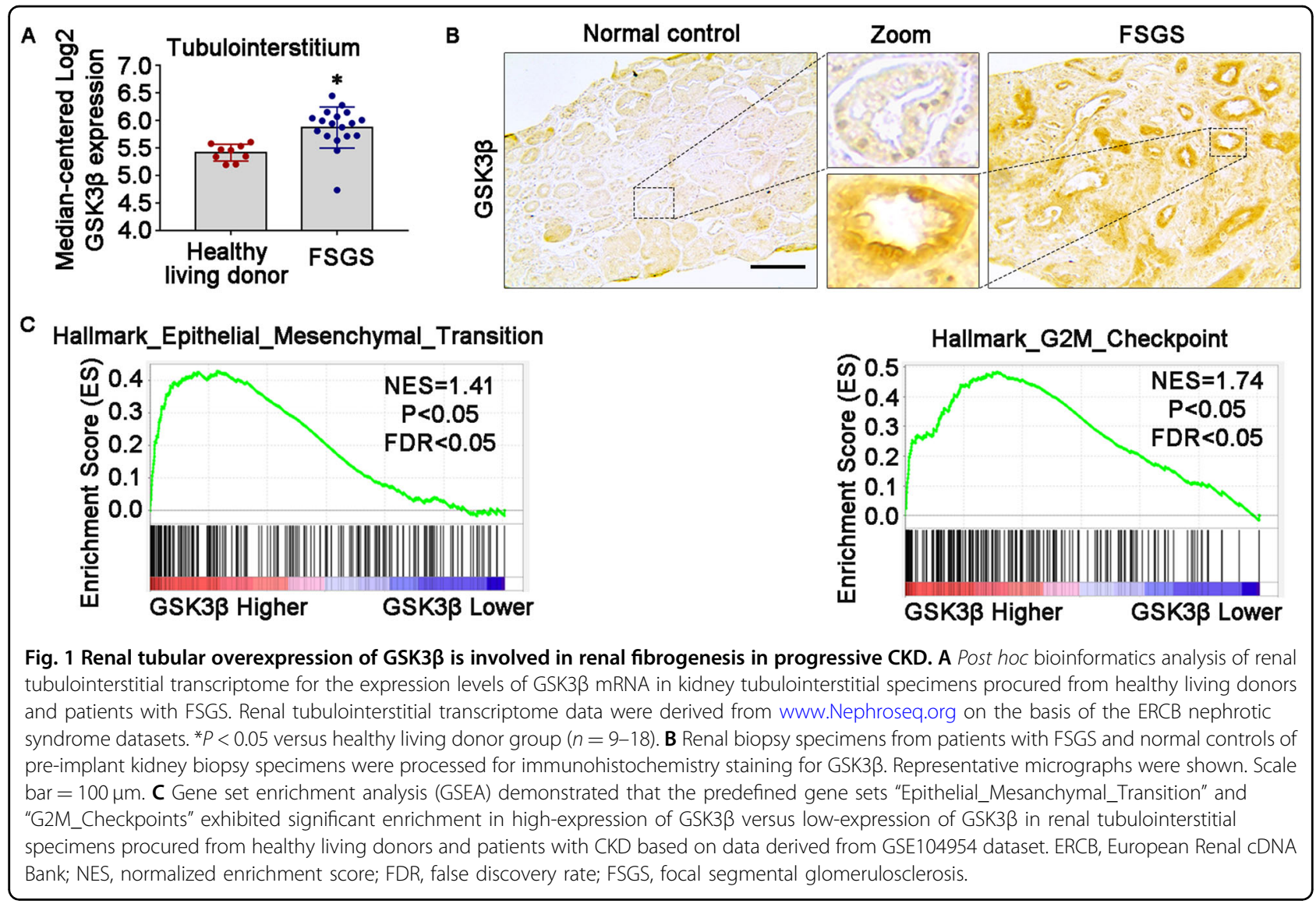

of GSK3 $\beta$ in progressive CKD, as opposed to normal controls, was profiled by a post hoc bioinformatics analysis of the publicly available kidney transcriptome database Nephroseq ${ }^{19}$. As shown in Fig. 1A, based on a dataset from ERCB in the Nephroseq database, mRNA expression levels of GSK3 $\beta$ in kidney tubulointerstitial specimens procured from patients with FSGS were significantly higher than those in healthy living donors. The kidney tubulointerstitium is known to consist of heterogeneous cell types, including renal TECs, vascular cells, and interstitial cells. To locate the expression of GSK3 $\beta$ in tubulointerstitium, renal biopsy specimens from patients with FSGS and pre-implant kidney biopsy specimens were subjected to immunohistochemistry staining for GSK3 $\beta$. In accordance with the above transcriptome data, immunostaining of GSK3 $\beta$ in renal tubulointerstitium was evidently more intense in FSGS patients as compared with normal controls. The upregulated expression of GSK3 $\beta$ was predominantly located in renal tubules (Fig. 1B).

Moreover, to determine whether GSK3 $\beta$ is involved in the kidney fibrogenic process, GSEA was performed based on the GSE104954 dataset (Tubulointerstitial transcriptome from ERCB subjects with CKD). As shown in Fig. $1 C$, the predefined hallmark gene sets implicated in fibrogenesis, including "Epithelial_Mesanchymal_Transition" and "G2M_Checkpoints", exhibited significant enrichment in high-expression of GSK3 $\beta$ versus lowexpression of GSK3 $\beta$ in kidney tubulointerstitial specimens procured from patients with CKD.

\section{Pharmacological inhibition of GSK3 $\beta$ attenuates the TGF- $\beta 1$ elicited renal TEC profibrogenic plasticity}

To further decipher the role of renal tubule-specific GSK3 $\beta$ in renal fibrogenesis, we employed an in vitro model of tubulointerstitial fibrosis, in which cultured murine TECs were treated with TGF- $\beta 1$, a prototype of profibrotic cytokines centrally implicated in renal fibro$\mathrm{sis}^{20,21}$. In agreement with the increased tubular expression of GSK $3 \beta$ in patients with progressive CKD, TGF- $\beta 1$ treatment induced the TEC expression of GSK3 $\beta$ in a dose and time-dependent fashion (Fig. 2A, B). This was associated with evident molecular changes of TEC profibrogenic plasticity, including loss of epithelial markers like E-cadherin adhesive junctions and ZO-1 tight junctions, acquisition of mesenchymal phenotypes like vimentin intermediate filaments, increased expression of fibrous ECM components like fibronectin, cell cycle arrest 


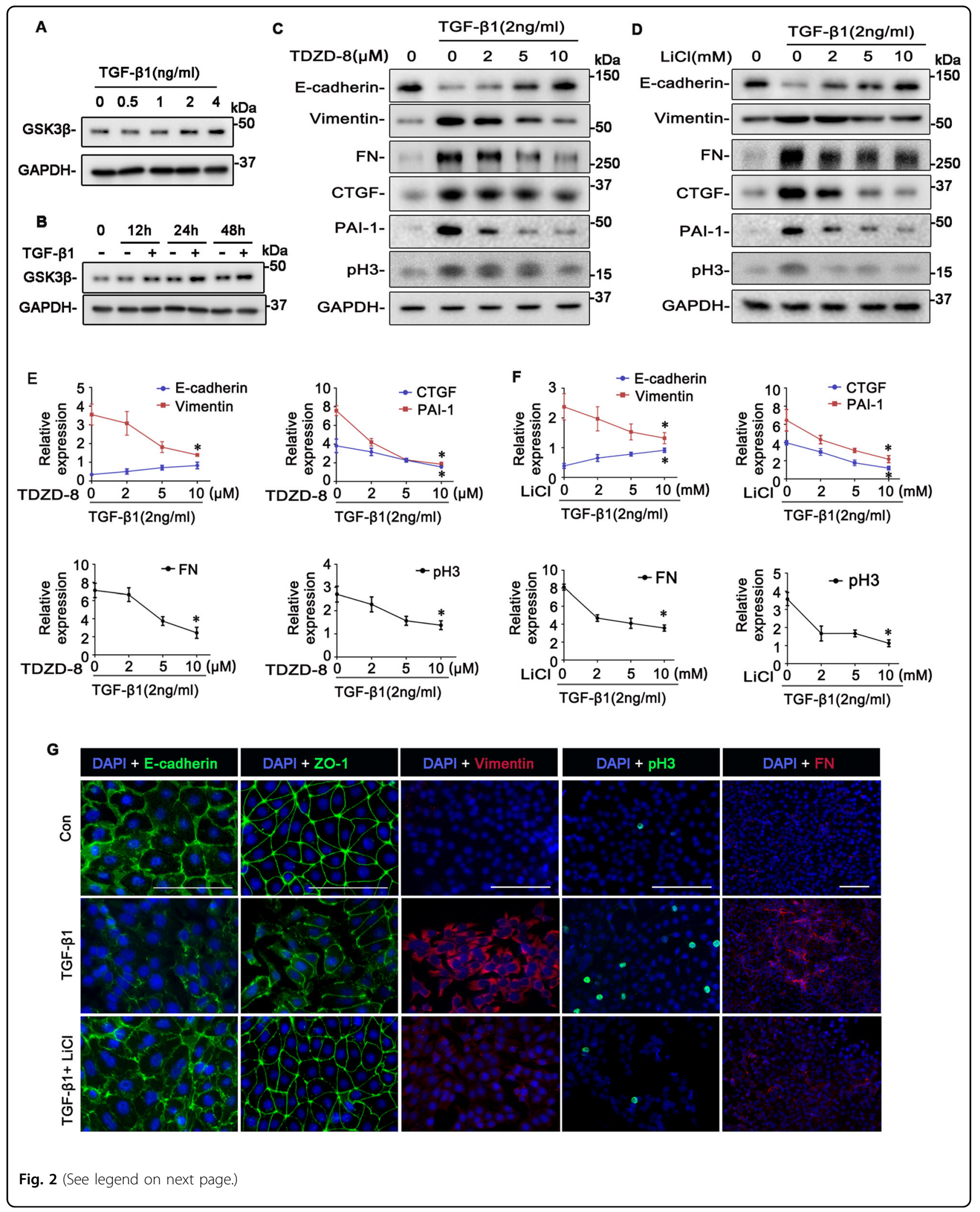


(see figure on previous page)

Fig. 2 Pharmacological inhibition of GSK3 $\beta$ by TDZD-8 or LiCl attenuates the TGF- $\beta 1$ induced TEC profibrogenic plasticity in a dosedependent fashion. A The immortalized murine renal proximal tubular epithelial cells (TKPT) were treated with or without TGF- $\beta 1$ ( $0.5,1,2,4 \mathrm{ng} / \mathrm{ml})$ for $24 \mathrm{~h}$. Cell lysates were prepared for immunoblot analysis for GSK3 $\beta$ and GAPDH. Representative immunoblots were shown. B TKPT were treated with or without TGF- $\beta 1(2 \mathrm{ng} / \mathrm{ml})$ for $12 \mathrm{~h}, 24 \mathrm{~h}$, or $48 \mathrm{~h}$. Cell lysates were prepared for immunoblot analysis for GSK3 $\beta$ and GAPDH. Representative immunoblots were shown. C TKPT were treated with TGF- $\beta 1(2 \mathrm{ng} / \mathrm{ml})$ for $24 \mathrm{~h}$ following pretreatment with different dose of TDZD-8 (0, 2, 5, $10 \mathrm{\mu mol} / \mathrm{L})$ or (D) $\mathrm{LiCl}(0,2,5,10 \mathrm{mmol} / \mathrm{L})$ for $30 \mathrm{~min}$. Cell lysates were prepared for immunoblot analysis for E-cadherin, vimentin, fibronectin (FN), PAI-1, CTGF, pH3, and GAPDH. Representative immunoblots were shown. E, F Densitometric analyses of the expression of E-cadherin, vimentin, FN, PAl-1, CTGF, and pH3, as normalized to the expression of GAPDH based on immunoblot analysis. ${ }^{*} P<0.05$ versus TGF- $\beta 1$ treatment group $(n=3$, t-test). G TKPT were treated with TGF- $\beta 1$ in the presence or absence of $\mathrm{LiCl}(10 \mathrm{mmol} / \mathrm{L})$ for $24 \mathrm{~h}$ and then fixed for immunofluorescent staining of E-cadherin, ZO-1, vimentin, pH3, and FN with nuclear counterstaining with DAPI. Representative fluorescent micrographs were shown. Scale bar $=$ $100 \mu \mathrm{m}$. CTGF, connective tissue growth factor; DAPI, 4',6-diamidino-2-phenylindole; FN, fibronectin; GAPDH, glyceraldehyde-3-phosphate dehydrogenase; PAl-1, plasminogen activator inhibition-1; pH3, phosphorylated histone H3; ZO-1, zonula occludens-1.

at the G2/M phase marked by de novo expression of $\mathrm{pH} 3$, and overproduction of profibrotic cytokines like CTGF and PAI-1, as measured by immunoblot analysis of cell lysates in combination with densitometry or by fluorescent immunocytochemistry staining of fixed cells (Fig. 2C-G). In parallel with the molecular changes, TECs underwent morphologic changes from the cobblestonelike cuboidal appearance of typical epithelial cells to a dispersed fusiform shape of mesenchymal cells (Fig. 3A). In contrast, blockade of GSK3 $\beta$ by the highly selective non-ATP competitive small molecule inhibitor TDZD-8, or by the classical inhibitor lithium salt, mitigated the TGF- $\beta 1$-induced molecular and morphologic changes of TEC profibrogenic plasticity in a dose and timedependent manner (Figs. 2 and 3).

\section{GSK3 $\beta$ regulates TGF- $\beta 1$-elicited TEC profibrogenic plasticity}

To determine if there is a direct causal relationship between GSK3 $\beta$ and TGF- $\beta 1$-induced TEC profibrogenic plasticity, the activity of GSK3 $\beta$ in cultured TECs was manipulated by forced expression of vectors encoding the HA-conjugated KD, or S9A with a transfection efficiency of more than $80 \%$, as estimated by immunostaining (Fig. 4A) and immunoblot analysis (Fig. 4B) for HA. After TGF- $\beta 1$ exposure, ectopic expression of the S9A mutant of GSK3 $\beta$ sensitized cell dedifferentiation, as evidenced by more reduction in Ecadherin expression and more induction of vimentin expression. Meanwhile, the potentiated production of fibronectin, PAI-1, and CTGF was also noted in S9Aexpressing cells. Besides, cell cycle arrest at the G2/M phase, shown by expression of $\mathrm{pH} 3$, was also amplified by forced expression of S9A (Fig. 4B). Conversely, all these molecular changes of TEC profibrogenic plasticity elicited by TGF- $\beta 1$ were blunted in KD-expressing cells (Fig. 4B), reminiscent of the effect of lithium or TDZD-8, entailing that GSK3 $\beta$ plays a permissive role in TGF- $\beta 1$ induced TEC profibrogenic plasticity.

\section{GSK3 $\beta$ regulates TGF- $\beta 1$ signaling in TECs via a CREB dependent mechanism}

Full activation of the TGF- $\beta 1 /$ Smad signaling pathway requires the binding of Smad proteins to several essential transcriptional coactivators, including the $\mathrm{CBP}^{22}$. Meanwhile, CREB also interacts with CBP and thus is able to compete for binding to CBP. Previous studies have shown that GSK3 $\beta$ regulates CREB signaling pathway in various cells $^{23-25}$. This prompted us to determine if GSK3 $\beta$ also dictates the activity of CREB in TECs and if this action affects the TGF- $\beta 1 /$ Smad signaling pathway. To this end, lithium or TDZD-8-treated TECs and S9A or KD-expressing TECs were injured with TGF- $\beta 1$. Cell lysates were subsequently subjected to immunoprecipitation with the anti-CBP antibody. Shown by immunoblot analysis of immunoprecipitates in Fig. 5A, inhibition of GSK3 $\beta$ activity by lithium or TDZD-8, or ectopic expression of KD augmented the amount of activated CREB (phosphorylated on serine 133) that coprecipitated with CBP, denoting a promotional effect of GSK3 $\beta$ inhibition on the activity of CREB and CBP recruitment to CREB. This was reciprocally associated with diminished binding of CBP to $\mathrm{p}$-Smad2, suggestive of repressed TGF- $\beta 1 /$ Smad signaling activity. Forskolin, a specific activator of adenylyl cyclase that raises levels of cAMP and triggers the CAMP-CREB signaling pathway, mimicked the effects of GSK3 $\beta$ inhibition and substantially abrogated the TGF- $\beta 1$ elicited molecular changes of TEC profibrogenic plasticity, as shown by immunoblot analysis and immunofluorescence staining (Fig. 5B-C), entailing that increased CREB activity is sufficient to mitigate the TGF- $\beta 1 / S m a d$ signaling in TECs and the consequent maladaptive plasticity. Conversely, increasing GSK3 $\beta$ activity by forced expression of S9A suppressed CBP binding to CREB but facilitated CBP recruitment to p-Smad2 (Fig. $5 \mathrm{~A}$ ), consistent with a reinforced TGF- $\beta 1 /$ Smad signaling activity. Taken together, the above findings suggest that GSK3 $\beta$ modulates the competition between CREB and Smad proteins for binding to the shared transcriptional coactivator CBP and that GSK3 $\beta$ inhibition offsets the TGF- $\beta 1 /$ Smad signaling activity that 


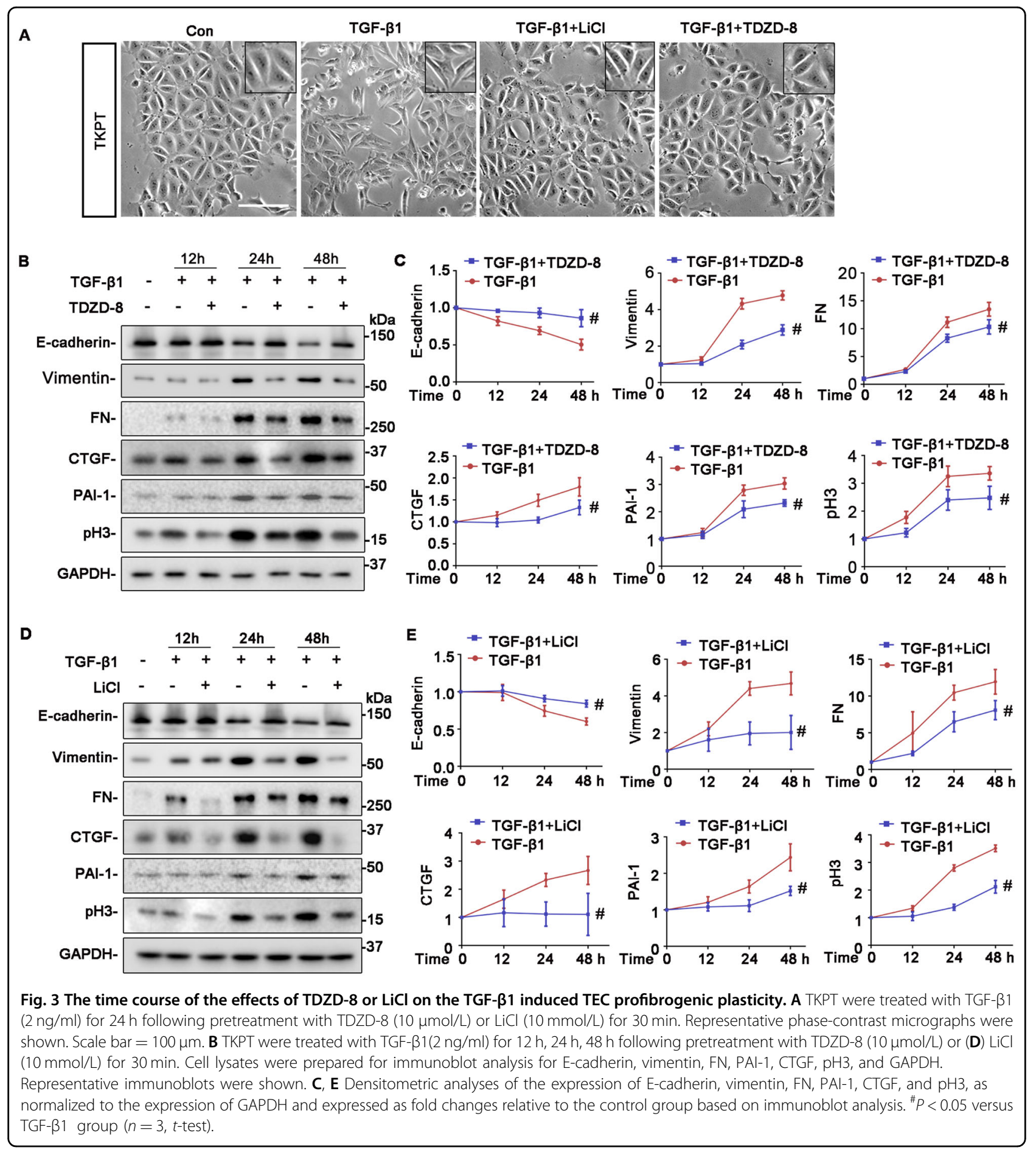

drives molecular changes of TEC profibrogenic plasticity in progressive CKD.

\section{Targeting of GSK3 $\beta$ in TEC improves kidney fibrosis in mice with FA nephropathy}

To validate the role of GSK3 $\beta$ in TEC profibrogenic plasticity and kidney fibrosis in vivo, we employed the
TEC-specific GSK3 $\beta$ KO mice (Fig. 6A), which were generated based on the Cre-loxP recombination technology by crossing GSK3 $\beta$-floxed mice with $\gamma \mathrm{GT}$. Cre transgenic mice, as confirmed by tail-snip genotyping (Fig. 6B). KO mice together with the control littermates were insulted by a single injection of FA $(250 \mathrm{mg} / \mathrm{kg})$. On day 7 after FA injection, mice received a microdose of 


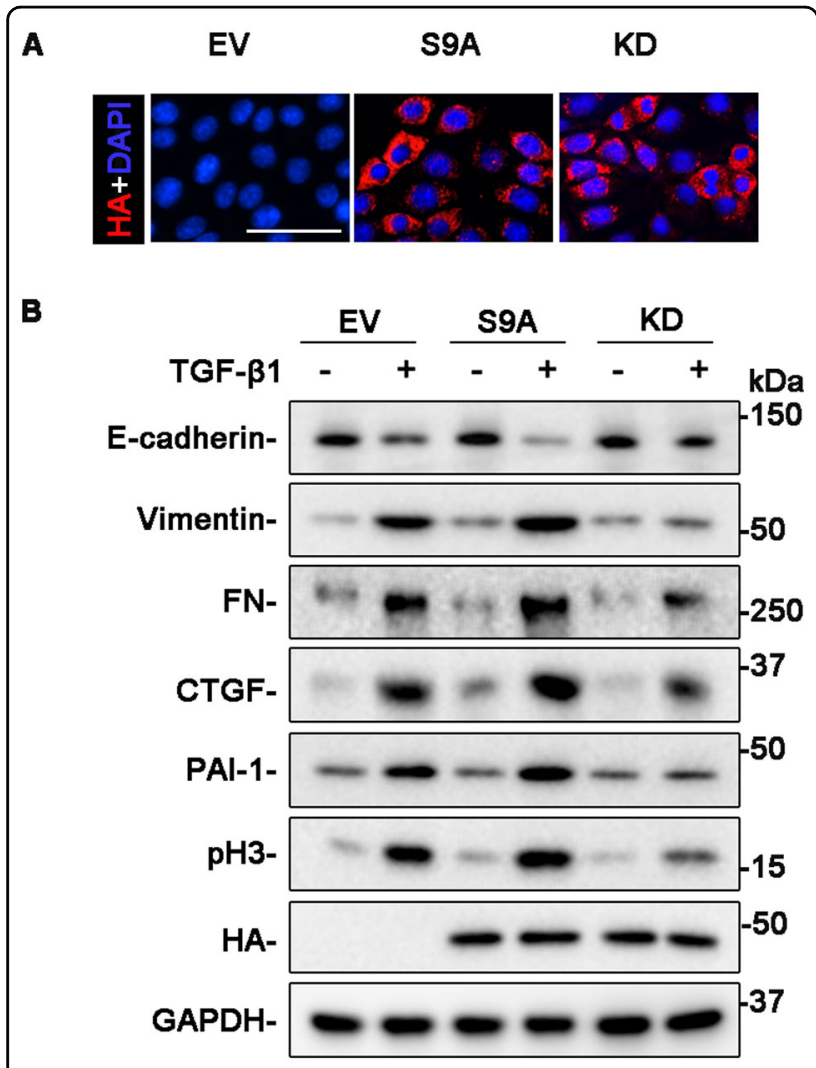

Fig. 4 The permissive effect of GSK3 $\beta$ on the TGF- $\beta 1$ induced TEC profibrogenic plasticity. TKPT were subjected to liposome-mediated transiently transfection with vectors encoding the empty vector (EV), dominant-negative (KD), or constitutively active (S9A) GSK3B.

A Representative micrographs of fluorescent immunocytochemistry staining for HA (red) with nuclear counterstaining with DAPI (blue). Scale bar $=50 \mu \mathrm{m}$. B After transfection, cells were treated with $2 \mathrm{ng} /$ $\mathrm{ml}$ of TGF- $\beta 1$ for $24 \mathrm{~h}$. Cell lysates were collected and subjected to immunoblot analysis for E-cadherin, vimentin, FN, PAI-1, CTGF, pH3, $\mathrm{HA}$, and GAPDH. Representative immunoblots were shown.

lithium $(40 \mathrm{mg} / \mathrm{kg})$ or an equal molar amount of sodium chloride-based on our previous experience ${ }^{9}$ and were followed up for another 7 days (Fig. 6C). FA injury elicited evident kidney dysfunction in control mice, marked by significant increases in serum BUN levels (Fig. 6D). In consistency, as shown by immunoblot analysis of kidney homogenates and by immunohistochemistry staining, renal expression of fibrous ECM components like fibronectin or collagen I was drastically increased, with the majority being located to renal tubulointerstitium (Fig. 6E-G), indicative of progressive CKD and kidney fibrosis. This coincided with GSK3 $\beta$ overexpression, denoting GSK3 $\beta$ hyperactivity. As expected, ablation of GSK3 $\beta$ in TECs or LiCl treatment successfully mitigated renal overexpression of GSK3 $\beta$ in FA-injured mice (Fig. 6E, F). This was associated with correction of renal dysfunction, as well as improvement in kidney fibrosis, as revealed by the lessened expression of fibronectin and collagen I. As a ubiquitously expressed kinase, GSK3 $\beta$ is also expressed in other kidney cells, such as fibroblasts, vascular endothelial cells, and inflammatory cells. It is plausible that GSK3 $\beta$ in other kidney cells may likewise play a role in kidney fibrosis, and is targetable by systemic lithium treatment but not by renal tubules-restricted GSK3 $\beta$ inhibition in KO mice. Indeed, as shown by immunoblot analysis and immunostaining for fibronectin or collagen I, lithium-treated mice had a tendency to achieve a greater anti-fibrotic efficacy than the $\mathrm{KO}$ mice.

\section{GSK3 $\beta$ facilitates TEC profibrogenic plasticity in FA-elicited progressive CKD}

Burgeoning evidence suggests that renal tubules undergo profibrogenic plasticity in progressive CKD and thereby play a key role in driving the development and progression of kidney fibrosis ${ }^{26}$. To assess renal tubule profibrogenic plasticity in the FA-injured mice, kidney specimens were processed for immunoblot analysis followed by densitometry. As shown in Fig. 7A-F, renal expression of E-cadherin, a renal TEC marker, plummeted in FA-injured control mice, in parallel with a substantial induction of vimentin intermediate filaments, a marker of mesenchymal phenotypes, and overproduction of profibrotic cytokines like PAI-1 and CTGF. To locate these molecular changes in the kidney, immunohistochemistry staining of kidney specimens was performed and demonstrated that loss of E-cadherin and increased expressions of vimentin, PAI-1, and CTGF were mainly localized to renal tubules (Fig. 7G), entailing renal tubular dedifferentiation and acquisition of profibrogenic phenotypes. This was concomitant with evident renal TEC cell cycle arrest at the G2/M phase, as probed by immunostaining for pH3 (Fig. 7G, H). All these molecular changes of renal tubular profibrogenic plasticity upon FA injury were markedly abrogated by lithium treatment or by GSK3 $\beta$ ablation in $\mathrm{KO}$ mice.

\section{GSK3 $\beta$ inhibition promotes CREB activity in renal tubules in FA-elicited progressive CKD}

To ascertain if GSK3 $\beta$ inhibition-improved renal tubular profibrogenic plasticity in FA nephropathy is associated with a change in the activity of CREB as posited by the above in vitro studies, kidney homogenates were processed for immunoprecipitation with anti-CBP antibody followed by immunoblot analysis. As shown in Fig. $8 \mathrm{~A}, \mathrm{~B}, \mathrm{GSK} 3 \beta$ inhibition by lithium treatment or by GSK3 $\beta$ ablation in $\mathrm{KO}$ mice considerably increased the amount of activated CREB that coprecipitated with CBP, denoting a promoted binding of CBP to CREB. This was reciprocally associated with reduced coprecipitation of p-Smad2 that with CBP, suggesting mitigated TGF- $\beta 1 /$ Smad signaling. Immunohistochemistry staining indicated 


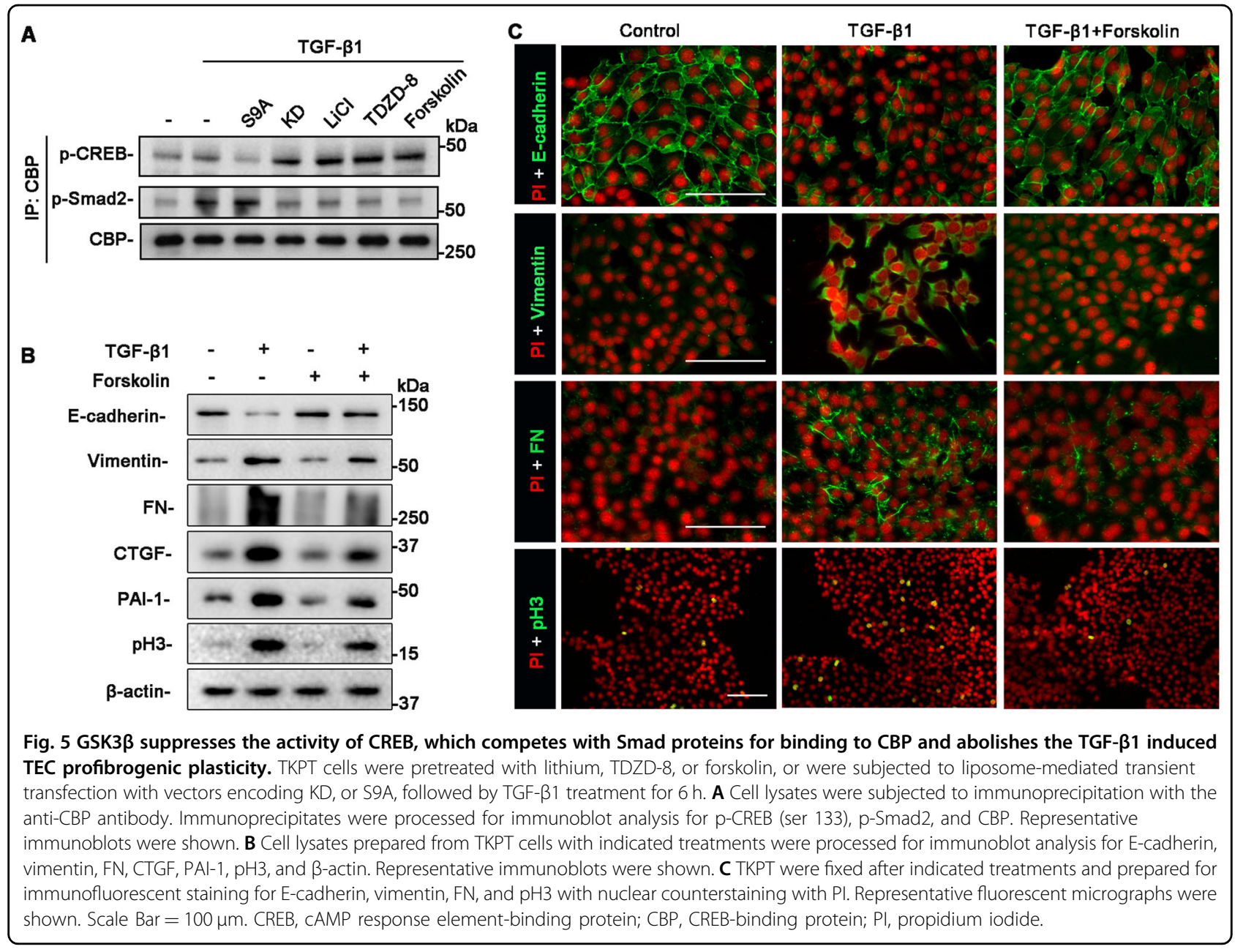

that the increased CREB activity occurred mostly in renal tubules in $\mathrm{KO}$ or lithium-treated mice (Fig. 8C).

\section{Discussion}

Renal tubulointerstitial fibrosis is the final common pathway for various CKDs that drives the progression to ESRD. The present work showed that GSK3 $\beta$ expression was amplified in renal tubular cells in patients with progressive $C K D$, as well as in both in vitro and in vivo models of renal fibrosis, concomitant with renal TEC fibrogenic plasticity. Moreover, targeting of GSK3 $\beta$ in renal tubules via genetic knockout or by lithium, a standard inhibitor of GSK3 $\beta$ and FDA-approved mood stabilizer, effectively preserved renal TEC phenotypes and ameliorated renal fibrosis in mice with FA nephropathy. To the best of our knowledge, this study is the first to demonstrate that renal tubule-specific GSK3 $\beta$ is involved in renal TEC fibrogenic plasticity and mediates renal fibrogenesis.

As a highly conserved serine/threonine kinase initially discovered to mediate the insulin signaling pathway and glycogen biosynthesis, GSK3 $\beta$ has also been implicated in many other pathophysiologic processes and conditions, including organ injury and repair, carcinogenesis, neurodegenerative diseases, and more recently kidney diseases $^{27}$. In the kidney, GSK3 $\beta$ is mainly expressed in glomeruli and proximal renal tubules ${ }^{14}$. Upon acute injuries, the activity of GSK3 $\beta$ in glomeruli or renal tubules is augmented secondary to the repressed inhibitory phosphorylation. This GSK3 $\beta$ hyperactivity has been shown to aggravate kidney cell death and acute renal injury via multiple mechanisms, including sensitization of mitochondria permeability transition, disruption of cytoskeleton integrity, and potentiation of NF$\kappa B$-dependent inflammatory responses ${ }^{28-30}$. In complementary studies, therapeutic targeting of GSK $3 \beta$ was able to protect against kidney dysfunction and mitigate acute renal injury in animal models of acute glomerulopathy $^{8}$ or $\mathrm{AKI}^{9}$, and improve the subsequent AKI to CKD transition ${ }^{31}$. Nevertheless, despite an unequivocal role of GSK3 $\beta$ in acute kidney diseases, it is not fully understood if GSK3 $\beta$ contributes to chronic renal 


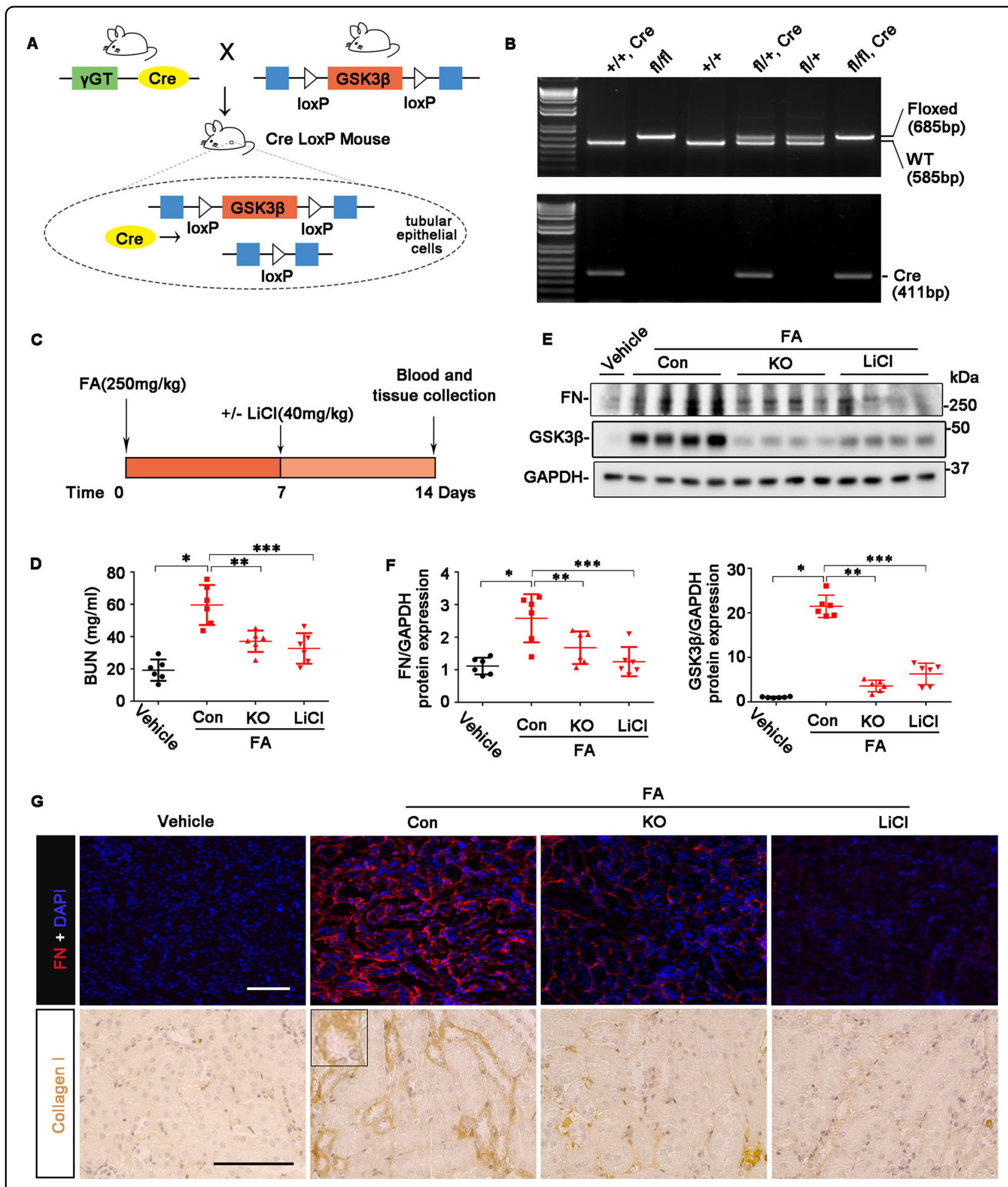

Fig. 6 (See legend on next page.) 
(see figure on previous page)

Fig. 6 Renal TEC-specific GSK3 $\beta$ gene deletion or lithium improves kidney fibrosis in folic FA-elicited progressive CKD. A Schematic diagram of the strategy for generation of mice with renal tubular epithelial cell-specific GSK3 $\beta$ gene knockout (KO). B Representative photos showing PCR analysis of the genomic DNA extracted from the clipped tail tissues. Genotypes of representative litters are indicated; fl, GSK3 $\beta$ floxed; WT, wild type. Mice with the genotype GSK3 $3 \beta^{f / f l}$, Cre were used as KO group. Control littermates served as control (Con). C The schematic diagram depicts the experimental design. Mice were injured with an injection of FA $(250 \mathrm{mg} / \mathrm{kg})$ and 7 days later were treated with or without $\mathrm{LiCl}(40 \mathrm{mg} / \mathrm{kg})$. Mice were followed up and euthanized on day 14 after FA injection, blood and kidney specimens were collected and processed for further examinations. D Quantification of blood urea nitrogen (BUN). ${ }^{* * *}{ }^{* *} P<0.05$ ( $n=6$, ANOVA followed by Tukey's test). E Kidney specimens were homogenized for immunoblot analysis for FN, GSK3 $\beta$, and GAPDH. Representative immunoblots were shown. $\mathbf{F}$ Densitometric analyses of the expression of FN and GSK3 $\beta$, as normalized to the expression of GAPDH and expressed as fold changes relative to the control group based on immunoblot analysis.

*,*****P $<0.05$ ( $n=6$, ANOVA followed by Tukey's test). G Representative micrographs of immunofluorescence staining for FN (red) with nuclear counterstaining with DAPI (blue), or immunohistochemistry staining for collagen I. Scale bar $=100 \mu \mathrm{m}$.

fibrogenesis and progressive CKD. Of note, the process of kidney fibrosis implicates multifarious kidney cells, including renal TECs, interstitial fibroblasts, vascular endothelial cells, and inflammatory cells. Among these, renal TECs are not only the target or victim of kidney injury but also a sine qua non of renal fibrotic changes. In progressive $C K D$, the persistent injury may cause TEC dedifferentiation, cell cycle arrest, and mesenchymal phenotypic switch, ultimately leading to excessive accumulation of fibrous ECM and kidney scarring ${ }^{26}$. Akin to the findings in the scenario of AKI, the activity of GSK3 $\beta$ in renal TECs is likewise augmented, marked by GSK3 $\beta$ overexpression, in diverse CKDs, such as diabetic nephropathy ${ }^{18}$, chronic allograft nephropathy ${ }^{15,32}$, and, in this study, FSGS and FA nephropathy. Our data indicated that this increased GSK3 $\beta$ activity may confer a permissive effect on TEC fibrogenic plasticity and contribute to renal fibrosis. Consistent with our findings, a number of studies also demonstrated that GSK3 $\beta$ exerts a pro-fibrotic effect in many other organ systems. For instance, inhibition of GSK3 $\beta$ by 9ING41, a highly selective small-molecule inhibitor, was able to improve bleomycin-induced pulmonary fibrosis in mice $^{33}$. In addition, morin, a dietary flavonoid, was able to reduce GSK3 $\beta$ expression in hepatic stellate cells and thereby meliorates diethylnitrosamine-induced liver fibrosis in rats ${ }^{34}$. Moreover, inhibition of GSK3 $\beta$ activity via cardiac-specific overexpression of dominant-negative GSK3 $\beta$ resulted in better left ventricular function and less fibrosis and apoptosis in mice subjected to transverse aortic constriction ${ }^{35}$.

TGF- $\beta 1$ signaling is one of the master signaling pathways in driving the development and progression of renal fibrosis. It acts on diverse renal parenchymal cells to induce cellular dedifferentiation, transdifferentiation, migration, and overproduction of fibrous ECM and profibrotic cytokines, such as PAI-1 and $\mathrm{CTGF}^{36}$. Most studies have focused on the effect of TGF- $\beta 1$ on fibroblast-like cells. However, there is data demonstrating that specific knockout of TGFBR2 in matrix-producing interstitial cells minimally diminished overall renal fibrosis in mice with unilateral ureteric obstruction (UUO) or aristolochic acid nephropathy ${ }^{37}$. This finding suggests that the effect of TGF- $\beta 1$ on non-fibroblast-like cells is also highly involved in the development of renal fibrosis. Indeed, Meng et al. selectively ablated TGFBR2 in renal TECs and showed a significant protective effect on UUOinduced renal fibrosis ${ }^{38}$. In renal TECs, TGF- $\beta 1$ acts through the TGFBR/Smad signaling to trigger molecular changes of profibrogenic plasticity. Then, how does GSK3 $\beta$ regulate the TGF- $\beta 1 /$ Smad signaling? Although the exact mechanism is still elusive, the following possibilities are in accordance with our findings and previous reports. It is likely that GSK3 $\beta$ is able to modulate the competition between Smad and CREB for binding to the shared transcriptional coactivator CBP, which is crucial for the full activation of TGF- $\beta 1 / \mathrm{Smad}$ signaling to trigger the TEC profibrogenic plasticity. In support of this, it has been well established that GSK3 $\beta$ is capable of modulating the activity of CREB in multiple cells, including immune cells, neurocytes, and fibroblasts ${ }^{39,40}$. In agreement, the present study showed that binding of activated CREB to CBP in TGF- $\beta 1$ treated renal TECs was enhanced after GSK3 $\beta$ inhibition but blunted by ectopic expression of S9A. How GSK3 $\beta$ regulates the activity of CREB is still poorly understood. It is known that phosphorylation of CREB at serine 133 is required for CBP recruitment, and the ensuing DNA binding and transcription ${ }^{41}$. However, the cognate phosphorylation site in CREB for GSK3 $\beta$ is not serine 133 but serine 129 as predicted by sequence analysis (data not shown) and validated by a number of studies $^{39,42}$. In accordance, phosphorylation of CREB at serine 133 creates the consensus sequence motif, SXXXS(P), thus priming CREB as a substrate for hierarchical phosphorylation of serine-129 by GSK $3 \beta^{39,43}$. It seems that phosphorylation of CREB by protein kinase A increased the DNA binding of CREB, whereas secondary phosphorylation of primed CREB by GSK3 $\beta$ attenuated protein kinase A stimulation of CREB DNA binding activity, implying that phosphorylation by 


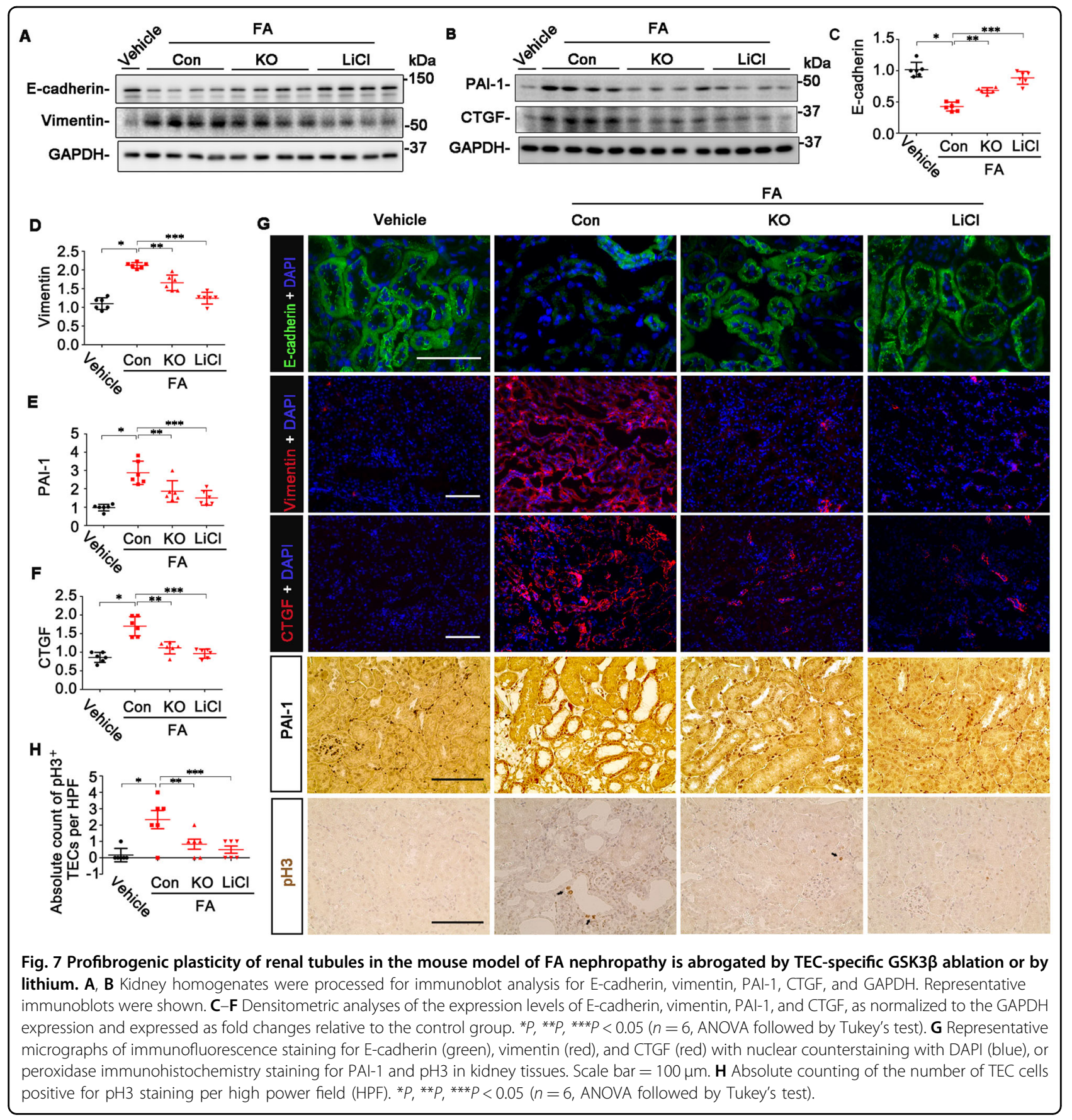

GSK3 $\beta$ at serine 129 acts as a suppressive signal for CREB activity ${ }^{39,42}$. This effect was likely attributable to changes in the conformational structure and net charges of CREB after GSK3 $\beta$-mediated phosphorylation ${ }^{42}$. This inhibitory effect of GSK3 $\beta$ on CREB activity has been reproducibly demonstrated in SH-SY5Y cells ${ }^{39}$, fibroblast cells ${ }^{23}$, and here again in renal TECs.

In summary, this study highlights a permissive effect of GSK3 $\beta$ on profibrogenic plasticity of renal TECs and renal fibrogenesis in progressive CKD. GSK3 $\beta$ modulates the competition between CREB signaling and TGF- $\beta 1 /$ Smad signaling for the recruitment of the shared transcriptional coactivator CBP. GSK3 $\beta$ inhibition intercepts the TGF- $\beta 1 /$ Smad signaling activity that drives molecular changes of TEC profibrogenic plasticity and ameliorates renal fibrosis in CKD (Supplementary Fig. 1). Our findings suggest that therapeutic targeting of GSK3 $\beta$ is likely a pragmatic approach to 


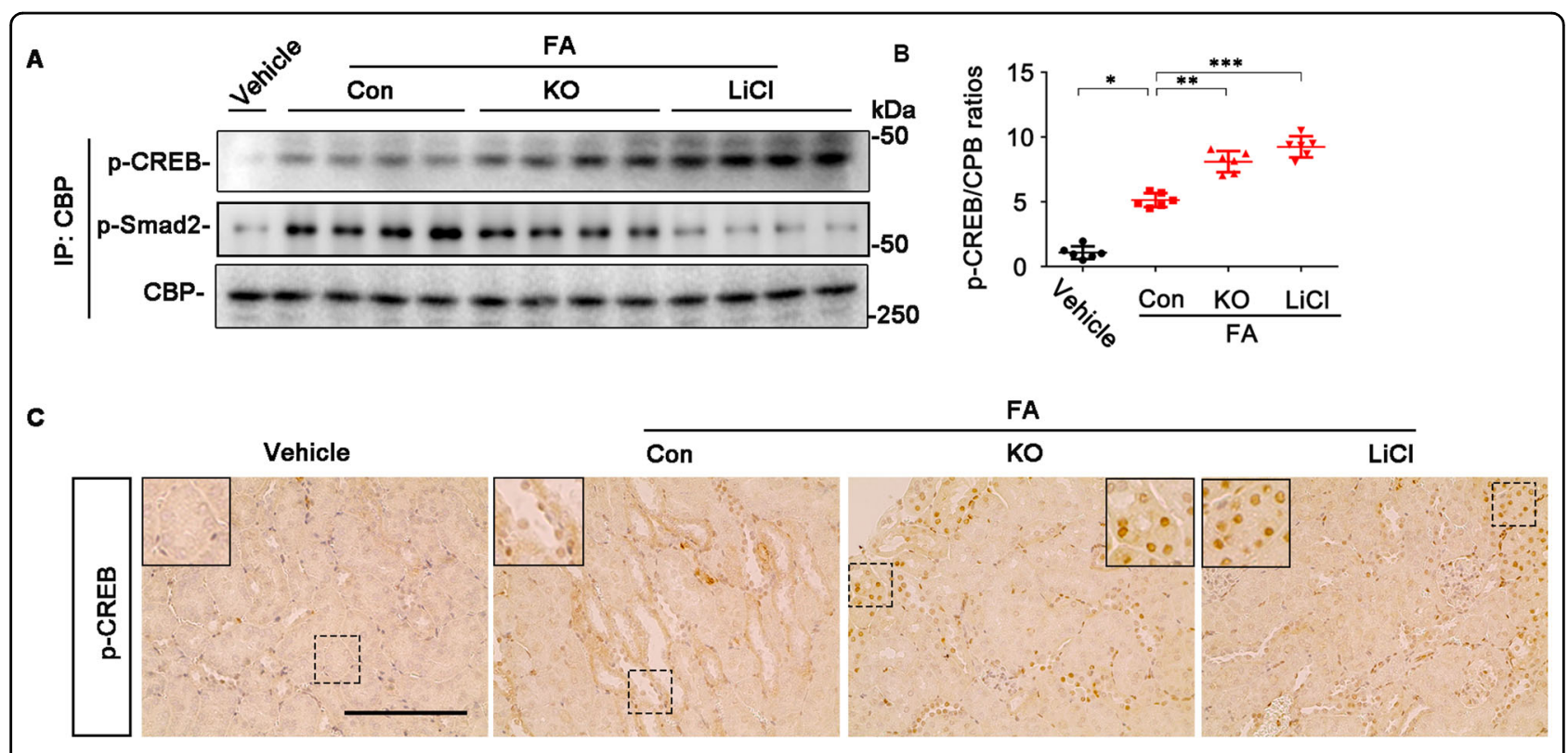

Fig. 8 GSK3 $\beta$ inhibition in mice with FA nephropathy increases CREB activity in renal tubules and favors CREB competition with Smad for binding to CBP. A Kidney homogenates were subjected to immunoprecipitation with the anti-CBP antibody and immunoprecipitates were processed for immunoblot analysis for indicated molecules. Representative immunoblots were shown. B Densitometric analysis of the levels of p-CREB that Co-precipitated with CBP, as normalized to the CBP levels and expressed as fold changes relative to the control group. ${ }^{*} P$, ${ }^{* *} P,{ }^{* * *} P<0.01$ ( $n=6$, ANOVA followed by Tukey's tests). C Representative micrographs of immunohistochemistry staining for $p$-CREB. Scale bar $=100 \mu \mathrm{m}$.

avert the maladaptive plasticity of renal TEC in progressive CKD and mitigate renal fibrosis.

\section{Acknowledgements}

The authors are grateful to all researchers involved in this work.

\section{Author contributions}

R.G. devised the conceptual ideas. B.C. and R.G. contributed to the study design. B.C. and X.L. carried out cell culture experiments. B.C., C.J., and Y.G. performed animal experiments and analyzed data. P.W., L.D.D., and R.G. contributed to the discussion and interpretation of the results. B.C. took the lead in writing the manuscript. R.G. contributed to manuscript editing. All authors agreed that the entire concept and ownership of this work belong to R.G. All authors approved the final manuscript.

\section{Funding}

Part of this study was presented at the American Society of Nephrology Kidney Week 2018 in San Diego. The research work was supported in part by the Foundation for Health. R.G. was supported by the U.S. National Institutes of Health grant DK092485 and DK114006. The funders had no role in the design and conduct of this study, collection, and interpretation of the data, or preparation and approval of the manuscript.

\section{Ethics statement}

Animal studies were carried out at the Rhode Island Hospital Central Animal Facility and were approved by the Rhode Island Hospital Institutional Animal Care and Use Committee, and conform to the United States Department of Agriculture regulations and the NIH's Guide for human care and use of Laboratory Animals.

\section{Conflict of interest}

The authors declare no competing interests.

\section{Publisher's note}

Springer Nature remains neutral with regard to jurisdictional claims in published maps and institutional affiliations.

Supplementary information The online version contains supplementary material available at https://doi.org/10.1038/s41419-021-03709-5.

Received: 5 February 2021 Revised: 11 April 2021 Accepted: 12 April 2021 Published online: 30 April 2021

\section{References}

1. Wynn, T. A. Cellular and molecular mechanisms of fibrosis. J. Pathol. 214, 199-210 (2008).

2. Takaori, K. et al. Severity and frequency of proximal tubule injury determines renal prognosis. J. Am. Soc. Nephrol. 27, 2393-2406 (2016).

3. Grgic, I. et al. Targeted proximal tubule injury triggers interstitial fibrosis and glomerulosclerosis. Kidney Int. 82, 172-183 (2012).

4. Lovisa, S. et al. Epithelial-to-mesenchymal transition induces cell cycle arrest and parenchymal damage in renal fibrosis. Nat. Med. 21, 998-1009 (2015).

5. Sakai, N. et al. Lysophosphatidic acid signaling through its receptor initiates profibrotic epithelial cell fibroblast communication mediated by epithelial cell derived connective tissue growth factor. Kidney Int. 91, 628-641 (2017).

6. Doble, B. W. \& Woodgett, J. R. GSK-3: tricks of the trade for a multi-tasking kinase. J. Cell Sci. 116, 1175-1186 (2003).

7. Li, C., Ge, Y., Dworkin, L., Peng, A. \& Gong, R. The beta isoform of GSK3 mediates podocyte autonomous injury in proteinuric glomerulopathy. J. Pathol. 239, 23-35 (2016).

8. Zhou, S. et al. Genetic and pharmacologic targeting of glycogen synthase kinase 3 beta reinforces the Nrf2 antioxidant defense against podocytopathy. J. Am. Soc. Nephrol. 27, 2289-2308 (2016).

9. Bao, $\mathrm{H}$. et al. Delayed administration of a single dose of lithium promotes recovery from AKI. J. Am. Soc. Nephrol. 25, 488-500 (2014).

10. Wang, Z. et al. GSK3beta promotes apoptosis after renal ischemic injury. J. Am. Soc. Nephrol. 21, 284-294 (2010). 
11. Bao, $H$. et al. Inhibition of glycogen synthase kinase-3 $\beta$ prevents NSAIDinduced acute kidney injury. Kidney Int. 81, 662-673 (2012).

12. Ge, Y. et al. Conditional ablation of glycogen synthase kinase $3 \beta$ in postnatal mouse kidney. Lab Invest. 91, 85-96 (2011).

13. Gong, R., Rifai, A., Ge, Y., Chen, S. \& Dworkin, L. D. Hepatocyte growth factor suppresses proinflammatory NFkappaB activation through GSK3beta inactivation in renal tubular epithelial cells. J. Biol. Chem. 283, 7401-7410 (2008).

14. Li, C., Ge, Y., Dworkin, L., Peng, A. \& Gong, R. The $\beta$ isoform of GSK3 mediates podocyte autonomous injury in proteinuric glomerulopathy. J. Pathol. 239, 23-35 (2016).

15. Gong, R. et al. Glycogen synthase kinase 3beta: a novel marker and modulator of inflammatory injury in chronic renal allograft disease. Am. J. Transpl. 8, 1852-1863 (2008).

16. Subramanian, A. et al. Gene set enrichment analysis: a knowledge-based approach for interpreting genome-wide expression profiles. Proc. Natl Acad. Sci. USA 102, 15545-15550 (2005).

17. Faul, F., Erdfelder, E., Lang, A. G. \& Buchner, A. G. Power 3: a flexible statistical power analysis program for the social, behavioral, and biomedical sciences. Behav. Res. Method 39, 175-191 (2007).

18. Liang, X. et al. Glycogen synthase kinase 3beta hyperactivity in urinary exfoliated cells predicts progression of diabetic kidney disease. Kidney Int. 97, 175-192 (2020).

19. Grayson, P. C. et al. Metabolic pathways and immunometabolism in rare kidney diseases. Ann. Rheum. Dis. 77, 1226-1233 (2018).

20. Lan, H. Y. Diverse roles of TGF- $\beta / S$ mads in renal fibrosis and inflammation. Int. J. Biol. Sci. 7, 1056-1067 (2011).

21. Meng, X. M., Tang, P. M., Li, J. \& Lan, H. Y. TGF- $\beta /$ Smad signaling in renal fibrosis. Front. Physiol. 6, 82 (2015).

22. Janknecht, R., Wells, N. J. \& Hunter, T. TGF-beta-stimulated cooperation of smad proteins with the coactivators CBP/p300. Genes Dev. 12, 2114-2119 (1998).

23. Baarsma, H. A. et al. Glycogen synthase kinase-3 (GSK-3) regulates TGF- $\beta_{1}$ induced differentiation of pulmonary fibroblasts. Br. J. Pharm. 169, 590-603 (2013).

24. Liang, M. H., Wendland, J. R. \& Chuang, D. M. Lithium inhibits Smad3/4 transactivation via increased CREB activity induced by enhanced PKA and AKT signaling. Mol. Cell Neurosci. 37, 440-453 (2008).

25. Tullai, J. W. et al. Glycogen synthase kinase-3 represses cyclic AMP response element-binding protein (CREB)-targeted immediate early genes in quiescent cells. J. Biol. Chem. 282, 9482-9491 (2007).

26. Gewin, L. S. Renal fibrosis: primacy of the proximal tubule. Matrix Biol. 68-69 248-262 (2018).

27. Patel, P. \& Woodgett, J. R. Glycogen synthase kinase 3: a kinase for all pathways? Curr. Top. Dev. Biol. 123, 277-302 (2017).

28. Wang, . et al. Valproate hampers podocyte acquisition of immune phenotypes via intercepting the GSK3 3 facilitated NFkB activation. Oncotarget 8 , 88332-88344 (2017)
29. Wang, Z. et al. Pharmacological targeting of GSK3 $\beta$ confers protection against podocytopathy and proteinuria by desensitizing mitochondrial permeability transition. Br. J. Pharm. 172, 895-909 (2015).

30. Bao, H., Ge, Y., Peng, A. \& Gong, R. Fine-tuning of NFkappaB by glycogen synthase kinase 3 beta directs the fate of glomerular podocytes upon injury. Kidney Int. 87, 1176-1190 (2015).

31. Lu, M. et al. GSK3ß-mediated Keap1-independent regulation of Nrf2 antioxidant response: A molecular rheostat of acute kidney injury to chronic kidney disease transition. Redox Biol. 26, 101275 (2019).

32. Yan, Q. et al. Expression of GSK-3 $\beta$ in renal allograft tissue and its significance in pathogenesis of chronic allograft dysfunction. Diagn. Pathol. 7, 5 (2012).

33. Jeffers, $A$. et al. Glycogen synthase kinase-3 $\beta$ Inhibition with 9-ING-41 attenuates the progression of pulmonary fibrosis. Sci. Rep. 9, 18925 (2019).

34. MadanKumar, P., NaveenKumar, P., Manikandan, S., Devaraj, H. \& NiranjaliDevaraj, S. Morin ameliorates chemically induced liver fibrosis in vivo and inhibits stellate cell proliferation in vitro by suppressing Wnt/ 3 -catenin signaling. Toxicol. Appl. Pharm. 277, 210-220 (2014).

35. Hirotani, S. et al. Inhibition of glycogen synthase kinase 3beta during heart failure is protective. Circ. Res. 101, 1164-1174 (2007).

36. Meng, X. M., Nikolic-Paterson, D. J. \& Lan, H. Y. TGF- $\beta$ : the master regulator of fibrosis. Nat. Rev. Nephrol. 12, 325-338 (2016).

37. Neelisetty, $\mathrm{S}$. et al. Renal fibrosis is not reduced by blocking transforming growth factor- $\beta$ signaling in matrix-producing interstitial cells. Kidney Int. 88, 503-514 (2015).

38. Meng, X. M. et al. Diverse roles of TGF- $\beta$ receptor $\|$ in renal fibrosis and inflammation in vivo and in vitro. J. Pathol. 227, 175-188 (2012).

39. Grimes, C. A. \& Jope, R. S. C. R. E. B. DNA binding activity is inhibited by glycogen synthase kinase-3 beta and facilitated by lithium. J. Neurochem. 78, 1219-1232 (2001)

40. Liu, X., Sun, S. Q., Hassid, A. \& Ostrom, R. S. cAMP inhibits transforming growth factor-beta-stimulated collagen synthesis via inhibition of extracellular signalregulated kinase 1/2 and Smad signaling in cardiac fibroblasts. Mol. Pharm. 70, 1992-2003 (2006).

41. Parker, D. et al. Phosphorylation of CREB at Ser-133 induces complex formation with CREB-binding protein via a direct mechanism. Mol. Cell Biol. 16, 694-703 (1996).

42. Bullock, B. P. \& Habener, J. F. Phosphorylation of the CAMP response element binding protein CREB by CAMP-dependent protein kinase $A$ and glycogen synthase kinase-3 alters DNA-binding affinity, conformation, and increases net charge. Biochemistry 37, 3795-3809 (1998).

43. Fiol, C. J. et al. A secondary phosphorylation of CREB341 at Ser129 is required for the CAMP-mediated control of gene expression. A role for glycogen synthase kinase-3 in the control of gene expression. J. Biol. Chem. 269 32187-32193 (1994) 